\title{
The use of a proximal protection system, a reperfusion catheter, and new-generation mesh stents in combined endovascular therapy for a long, symptomatic dissection of the right internal carotid artery
}

\author{
Paweł Latacz'1, Marian Simka², Tadeusz Popiela³ \\ 1 Department of Neurology, Jagiellonian University Medical College, Kraków, Poland \\ 2 Department of Anatomy, University of Opole, Opole, Poland \\ 3 Chair of Radiology, Jagiellonian University Medical College, Kraków, Poland
}

Correspondence to:

Paweł Latacz, MD, PhD, Department of Neurology, Jagiellonian University Medical College, ul. Jakubowskiego 2, 30-688 Kraków, Poland, phone: +48124002551, email: pawlat@me.com Received: March 16, 2020. Revision accepted: April 15, 2020. Published online: April 22, 2020. Kardiol Pol. 2020; 78 (6): 597-598 doi:10.33963/KP.15305 Copyright by the Author(s), 2020
Dissection of the carotid arteries is a significant cause of cerebral ischemic events, including stroke. This condition can occur spontaneously, but it also may be of traumatic etiology. ${ }^{1-3}$ Importantly, traumatic injuries of the carotid arteries are associated with significant morbidity and mortality.

Here, we present a case of endovascular repair (ER) of such a traumatic lesion of the internal carotid artery in a 46-year-old man. The patient presented with a recent history of blunt injury of the neck (due to a bicycle accident) and developed symptoms of ischemia of the right hemisphere. No clinical improvement was seen after conservative management. Therefore, invasive diagnostic workup of the cerebral arteries was performed. Catheter angiography revealed a dissection from the $\mathrm{C} 1$ (cervical) to the $\mathrm{C} 4$ / C5 (cavernous / clinoid) segments of the right internal carotid artery (ICA), with a large residual thrombus in the C5 segment (FIGURE 1A).

Endovascular repair was performed with proximal protection, using the 8F Mo.Ma device (Medtronic, Minneapolis, Minnesota, United States). Over the Transend guidewire (Boston Scientific, Natick, Massachusetts, United States), which was advanced into the distal part of the right middle cerebral artery, we introduced the 5F Sofia reperfusion catheter (Microvention, Aliso Viejo, California, United
States) and aspirated the thrombi (FIGURE 1B and 1C). Then, in order to cover the dissection, we implanted 2 RoadSaver stents (Terumo, Tokyo, Japan): the first of $5 \times 30 \mathrm{~mm}$ and the other of $6 \times 30 \mathrm{~mm}$ in size (FIGURE 1D). Peri- and postprocedural clinical course was uneventful in our patient. He was discharged from the hospital and recommended to continue dual antiplatelet therapy for at least 6 months. The patient was asymptomatic at 4-month follow-up after ER.

Carotid dissections are preferably managed conservatively. Still, in about $2 \%$ of patients, pharmacologic treatment is unsuccessful and another episode of ischemia occurs. ${ }^{3}$ On the other hand, ER is associated with a high risk of serious adverse events occurring with a frequency of $16 \% .^{2,4,5}$ Interestingly, although the majority of these complications is associated with cerebral embolism, protection devices are rarely used in this patient population (the percentage of patients managed with protection does not exceed 20\%). ${ }^{4,5}$ Of note, cerebral hypoperfusion associated with proximal protection is much less harmful than embolism. Carotid occlusion related to the use of a protection device lasts 3 to 10 minutes, which seems to be safe, particularly if adequate circulation is present in the circle of Willis. It should be emphasized that ER of carotid dissections, although life-saving, should be performed exclusively in 

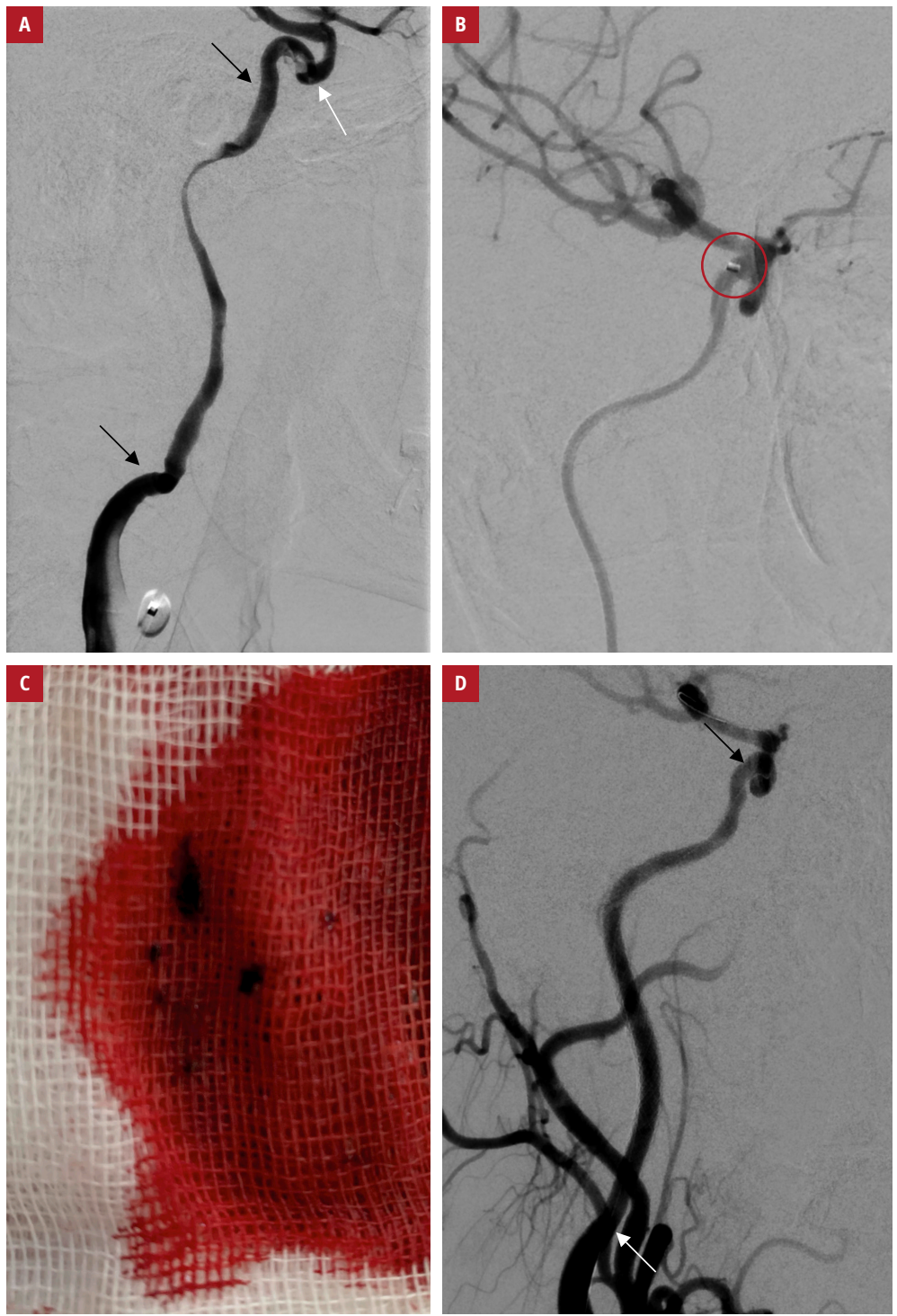

FIGURE 1 A patient with symptomatic dissection of the carotid artery after blunt injury of the neck: $\mathbf{A}$ - angiography showing a long dissection of the right internal carotid artery from the C1 to $C 4$ segments (the dissection is seen between the black arrows; the white arrow shows a residual thrombus in the $(5$ segment); $\mathbf{B}$ - angiography showing the thrombi removed with the Sofia catheter (the circle indicates the catheter tip); $\mathbf{C}$ - the thrombi removed through the reperfusion catheter; $\mathbf{D}$ - postprocedural angiography (left anterior oblique projection) showing the final result after implanting 2 RoadSaver stents; the arrows indicate the beginning and the end of the stents the artery caused by the dissection. In addition, in contrast to stents, which are intended to treat intracranial aneurysms, the RoadSaver stents have adequate radial force that minimizes the risk of early stent occlusion.

\section{ARTICLE INFORMATION}

\section{CONFLICT OF INTEREST None declared.}

OPEN ACCESS This is an Open Access article distributed under the terms of the Creative Commons Attribution-Non Commercial-No Derivatives $4.0 \mathrm{In}$ ternational License (CC BY-NC-ND 4.0), allowing third parties to download articles and share them with others, provided the original work is properly cited, not changed in any way, distributed under the same license, and used for noncommercial purposes only. For commercial use, please contact the journal office at kardiologiapolska@ptkardio.pl.

HOW TO CITE Latacz P, Simka M, Popiela T. The use of a proximal protection system, a reperfusion catheter, and new-generation mesh stents in combined endovascular therapy for a long, symptomatic dissection of the right internal carotid artery. Kardiol Pol. 2020; 78: 597-598. doi:10.33963/KP.15305

\section{REFERENCES}

1 Bogousslavsky J, Pierre P. Ischaemic stroke in patients under age 45. Neurol Clin. 1993; 10: 113-124.

2 Kremer C, Mosso M, Georgiadis D, et al. Carotid dissection with permanent and transient occlusion or severe stenosis: Iong-term outcome. Neurology. 2003; 60: 271-275.

3 Markus HS, Hayter E, Levi C, et al; CADISS trial investigators. Antiplatelet treatment compared with anticoagulation treatment for cervical artery dissection (CADISS): a randomised trial. Lancet Neurol. 2015; 14: 361-367.

4 Donas KP, Mayer D, Guber I, et al. Endovascular repair of extracranial carotid artery dissection: current status and level of evidence. J Vasc Interv Radiol. 2008; 19: 1693-1698.

5 Kurre W, Bansemir K, Aguilar Pérez M, et al. Endovascular treatment of acute internal carotid artery dissections: technical considerations, clinical and angiographic outcome. Neuroradiology. 2016; 58: 1167-1179. centers having high expertise in neurovascular interventions.

Our patient was managed with proximal protection, which enabled safe aspiration of thrombi from the distal part of the dissected artery. The dissected part of the ICA was covered with the RoadSaver stents. These stents, with a double-layer micromesh design, prevent the protrusion of thrombi and plaques through the struts. They are also relatively easy to deploy in the intracranial segments of the ICA, since their low profile makes the device crossable through the tortuous sections of this vessel. Also, such a stent can be used as a flow-diverting device, excluding aneurysmatic dilatation of 